\title{
Realocação em Sistemas de Compartilhamento de Veículos em Uma Via
}

\author{
Felipe Rooke $^{1}$, Victor Aquiles Alencar ${ }^{1}$, Marcelo de O. C. Machado ${ }^{2}$, \\ Alex Borges Vieira ${ }^{1}$ \\ ${ }^{1}$ Departamento de Ciência da Computação - UFJF \\ ${ }^{2}$ Pós-Graduação em Informática - UNIRIO \\ felipe.rooke@ufjf.edu.br, victoraquiles@ice.ufjf.br \\ marcelo.machadodedu.unirio.br, borgesedcc.ufmg.br
}

\begin{abstract}
The understanding of urban mobility is useful to create more intelligent and sustainable cities. Currently, car-sharing services add more dynamism to transportation in cities. However, some modalities of these services occasionally present imbalances of vehicles in the regions of operation. That is, one region holds too many vehicles, while in others, vehicles are scarce. Thus, this paper presents a characterization of a car-sharing system, operating in Vancouver and nearby regions, revealing some patterns of use and demand of users. In addition, discussions were presented that support the resolution of the problem addressed and that can contribute to the evolution of these systems.
\end{abstract}

Resumo. A compreensão da mobilidade urbana é útil para criação de cidades mais inteligentes e sustentáveis. Atualmente, serviços de compartilhamento de veículos agregam maior dinamismo ao transporte nas cidades. Entretanto, algumas modalidades desses serviços ocasionalmente apresentam desbalanceamentos de veículos nas regiões de atuação. Isto é, uma região detém demasiada quantidade de veículos, enquanto em outras, os veículos estão escassos. Assim, este trabalho apresenta uma caracterização de um sistema de compartilhamento de veículos, que opera em Vancouver e regióes próximas, revelando alguns padrões de uso e de demanda dos usuários. Ainda, foram apresentadas discussões que dão suporte a resolução do problema abordado e que podem contribuir para a evolução desses sistemas.

\section{Introdução}

Mobilidade urbana é uma área chave e atrai estudos acadêmicos e investimentos privados. Ela está fortemente atrelada a diversas atividades urbanas, como a demanda por recursos de comunicação. Além disso, a massificação dos dispositivos móveis tornou o acesso a rede ubíquo e centrado no usuário. Nesse cenário, compreender a mobilidade urbana, em específico no trânsito, é importante para uma série de tarefas, desde planejamento das malhas viárias aos recursos de comunicação [Herrera et al. 2010, Ma et al. 2013].

O primeiro passo para compreender padrões de mobilidade urbana é a obtenção de dados. Entretanto, essa é uma tarefa desafiadora, onde em muitos casos, poucas empresas têm acesso a dados acurados e atuais e, na maioria das vezes, esses dados são sensíveis 
com relação a privacidade [Ciociola et al. 2017]. Assim, é importante gerar modelos que possam representar os padrões de mobilidade urbana e suas interações sociais.

Atualmente, sistemas de compartilhamento de veículos (car-sharing) têm recebido crescente atenção da comunidade acadêmica [Boldrini et al. 2016, Ciociola et al. 2017, Becker et al. 2017]. Esses sistemas permitem que as pessoas agendem o uso de um veículo e realize suas tarefas cotidianas, sem se preocupar com manutenção, estacionamento e impostos. Esses sistemas apresentam grande volume de usuários e podem ser representativos quanto aos padrões de mobilidade urbana. De fato, até 2015 foram contabilizados mais de 1,5 milhão de usuários e mais de 22 mil veículos compartilhados nas Américas - com previsão de crescimento [Shaheen 2016].

Existem três principais modelos de negócio para operação de serviços de compartilhamento de veículos [Nourinejad 2014]: (1) serviços de uma via (one-way), onde existem estações bases espalhadas em uma região e o usuário pode alugar um veículo em uma estação e deixá-lo em outra; (2) serviços de duas vias (two-way), onde o usuário aluga um veículo e deve deixá-lo na mesma estação que o retirou e (3) serviços flutuantes (freefloating), onde não há a necessidade de estações base e o usuário fica livre para alugar um veículo e deixá-lo em qualquer região de operação do serviço [Boldrini et al. 2016].

Um problema associado aos serviço one-way e free-floating é o desbalanceamento de veículos em determinadas regiões ou estações. Devido a uma demanda de saída elevada de veículos em determinado local, e a uma entrada não equivalente, possivelmente menor, aquele local pode ficar desabastecido. Por outro lado, outras localizações cuja demanda de saída não é elevada, podem ficar com excesso de veículos. Realizar a realocação de veículos pode ser muito custoso para um operador, portanto, nesse contexto, estudos para identificar melhores estratégias de realocação estão sendo desenvolvidos.

Neste trabalho, foi caracterizado o $E v 0^{1}$, um serviço importante de compartilhamento de veículos. As caracterizações conduzidas evidenciam os padrões de uso desse sistema e desbalanceamentos que ocorrem em seu uso. Foram caracterizados aspectos espaço-temporais que servem de substrato para o desenvolvimento de algoritmos de realocação de veículos, com foco na economia e redução de custos operacionais.

O restante do artigo está organizado como segue: a Seção 2 descreve os modelos de compartilhamento de veículos bem como trabalhos relacionados; a Seção 3 expõe a metodologia do trabalho; a Seção 4 propõe uma caracterização relacionada a base de dados da Evo; a Seção 5 discute e apresenta propostas de trabalhos futuros para realocação de veículos a partir da caracterização apresentada e, por fim, a Seção 6 conclui o trabalho.

\section{Modelos de compartilhamentos de veículos e trabalhos relacionados}

De maneira geral, um usuário localiza e agenda um carro através do aplicativo, se desloca até ele, e realiza seu destrancamento também pelo smartfone. Alguns serviços, solicitam que o usuário inspecione o veículo, em busca de algum tipo de dano, antes de iniciar seu uso. Quando um usuário realiza o destrancamento de um veículo, seu aluguel começa a ser contabilizado. Após a utilização, o usuário deve retornar com o veículo a uma estação ou a um estacionamento público, a depender do modelo de negócio do serviço.

De forma ampla, existem dois modelos de negócios de compartilhamento de

\footnotetext{
${ }^{1}$ https: //www.evo.ca/
} 
veículos: os baseados em estações e os flutuantes. Nos modelos baseados em estações, o usuário deve se dirigir a um local específico onde se encontram os veículos. No modelo flutuante, os veículos não têm localização específica e se encontram espalhados em zonas de atuação do serviço (home zone). Ainda, os serviços baseados em estações podem ser de uma ou duas vias.

A dinâmica da demanda dos sistemas de uma via e flutuante pode, em alguns casos, tornar os veículos escassos em algumas regiões. Ocasionalmente, locais onde são originadas muitas viagens, ficam desabastecidos de veículos, enquanto outros, onde ocorre o inverso, muitas viagens se destinam a eles, ficam saturados. Periodicamente, os operadores dos serviços, realocam veículos entre os locais onde existe essa necessidade. Comumente, é definido um limite superior e inferior da quantidade de veículos em cada local, e esse, é verificado para alertar quando as realocações devem ser realizadas [Kek et al. 2009]. Efetuar realocações pode ser muito custoso para os operadores. Portanto, as estratégias de realocação também devem observar se os ganhos da estratégia compensam o custo de realocação [Weikl and Bogenberger 2013].

Atualmente existem três tipos de estratégias de realocação, a realocação baseada no usuário (User-Based), a baseada no operador (Operator-Based) e uma estratégia híbrida, combinando as estratégias anteriores. A estratégia de realocação baseada no usuário, é comumente realizada mediante bônus e reduções de tarifas no aluguel dos veículos, caso o usuário percorra determinado trajeto, estipulado pela operadora. Essa estratégia tem um baixo custo de implantação. Além disso, apresenta um efeito a médio e longo prazo, por exemplo, condicionando um usuário a incluir a utilização do serviço em sua rotina para determinado trajeto [Weikl and Bogenberger 2013]. A realocação baseada no operador, apresenta uma clara diferença da estratégia anterior, pois a operadora do serviço intervém diretamente na realocação dos veículos. Agentes ficam responsáveis por realizar a movimentação de veículos de um local a outro. Essa estratégia é mais custosa que a anterior, no entanto sua execução ocorre em curto prazo, com operações bem definidas, com hora de início e fim [Weikl and Bogenberger 2013]. Finalmente, tem-se a estratégia híbrida. Um exemplo de cenário onde essa estratégia pode ser adotada é quando há uma situação onde é necessária uma ação a curto prazo e, no entanto, já existe uma realocação baseada em usuários acontecendo. Nesse caso, uma realocação baseada no operador seria realizada [Weikl and Bogenberger 2013].

A Figura 1 apresenta um modelo de dois passos para realocações de veículos em serviços de compartilhamento de veículos flutuantes. Nesse sistema há o Módulo de Demanda Offline e o de Otimização Online. O primeiro fornece uma análise das demandas de grupos identificados no serviço, e também a predição da demanda. Os resultados desse módulo fornecem informações para a predição da disponibilidade espacial ideal futura dos veículos do serviço. O segundo mede a diferença entre a disponibilidade espacial ideal futura e o estado atual do serviço. Além disso, é responsável por decidir o melhor momento de realocação e qual estratégia utilizar.

O Módulo de Demanda Offline é executado periodicamente. A ideia é realizar a análise de padrões de demanda que são repetidos ao longo do tempo e espaço. O primeiro passo nesse módulo, é a aquisição dos dados a serem analisados. É importante que seja possível identificar características espaciais e temporais nesses dados. O próximo passo, é o agrupamento e análise dos dados. Esse passo pode ser executado de diversas formas, 


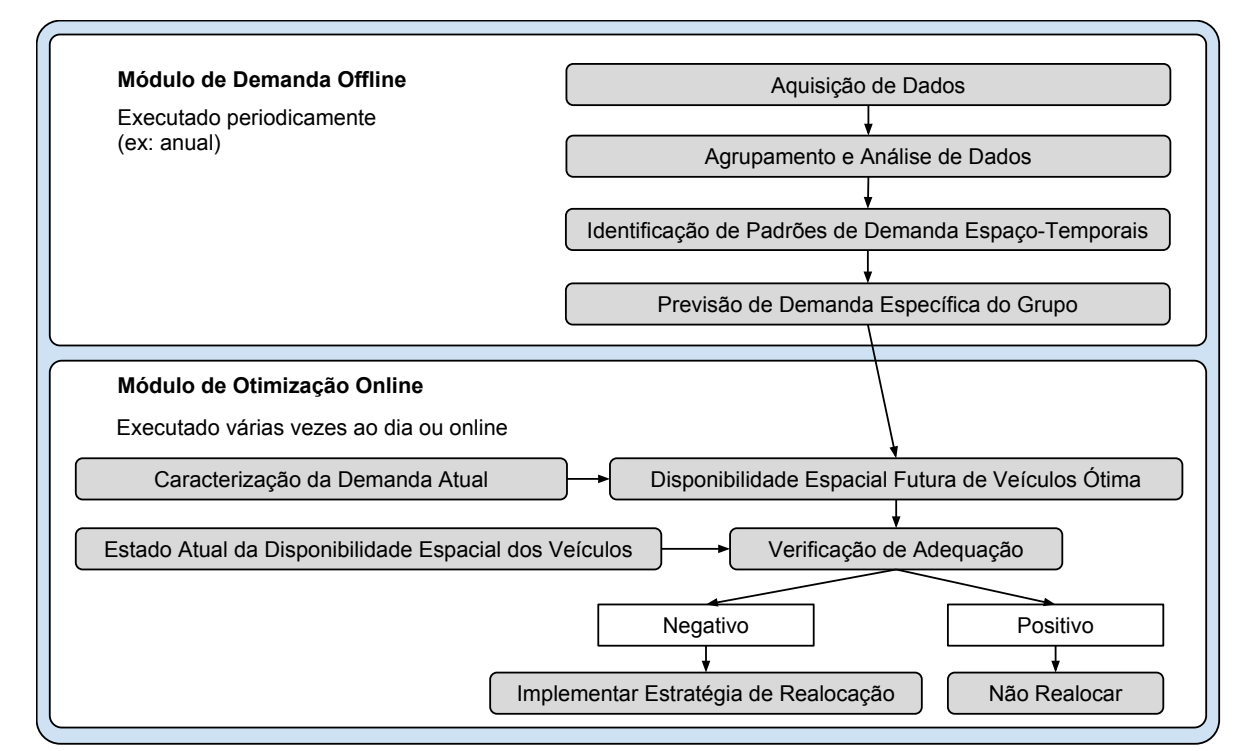

Figura 1. Modelo de dois passos para realocação de veículos em sistemas de compartilhamento de veículos (Adaptação do modelo proposto por [Weikl and Bogenberger 2013])

utilizando algoritmos de agrupamento conhecidos, agrupando por regiões da cidade, utilizando um critério de agrupamento próprio, entre outros. Assim que definido os grupos, o próximo passo é a caracterização, onde são identificado os padrões de demanda espaçotemporais de cada grupo. Por ultimo, é criado um modelo que permite a previsibilidade das demandas específicas de cada grupo.

O Módulo de Demanda Online é executado constantemente. Ele é responsável por verificar a demanda atual do serviço e juntamente com as informações fornecidas pelo módulo Offline, efetuar a tomada de decisão sobre a realocação. Nesse módulo, é feita uma caracterização da demanda corrente do serviço com informações recentes. Essa caracterização, juntamente com as informações fornecidas pelo módulo Offline, definem qual seria a disponibilidade espacial futura ótima dos veículos no momento observado. Uma vez que isso está definido, é possível verificar o estado atual da disponibilidade espacial dos veículos e verificar se está adequada ou não à disponibilidade futura ótima. Caso não esteja, o módulo implementa e sugere uma estratégia de realocação.

Neste trabalho, exploramos partes do Módulo de Demanda Offline, proposto no modelo de dois passos para realocação de veículos em sistemas de compartilhamento de veículos. Utilizamos um método de agrupamento e discretização para definição dos grupos cujas demandas foram posteriormente caracterizadas. Além disso, acreditamos que as características observadas fornecem subsídios para apoiar tanto estratégias baseadas no usuário, quanto estratégias baseadas no operador.

\section{Estrutura da pesquisa}

Este estudo se baseia em dados de utilização do serviço de compartilhamento de veículos Evo. Esse é um serviço conhecido e que opera na cidade de Vancouver (Canadá) e regiões próximas. O Evo não oferece uma API pública para pesquisadores. Por isso, foram coletados dados que estão disponíveis publicamente em seu portal web. A cada minuto, uma lista de todos os veículos existentes no serviço foram coletadas. Nesse mesmo intervalo de 
tempo foram coletadas informações daquele instante (snapshot) do serviço, descrevendo quais veículos estão estacionados, onde estão e se estão disponíveis para viagem.

Todos os snapshots do sistema foram processados para inferir os momentos em que o veículo estava ocupado (alugado) ou ocioso (estacionado em uma estação). Durante um snapshot, se um veículo está listado entre os veículos do sistema, mas não estiver estacionado em nenhuma estação, infere-se que o mesmo está em uso. Então, foi configurado o ponto de partida de uma nova viagem como a última estação em que o veículo estava estacionado. Analogamente, o ponto final da viagem será a próxima estação em que o veículo aparecer disponível em um snapshot futuro. O tempo total da viagem é contabilizado como a diferença entre os tempos dos dois snapshots.

Assim, a coleta dos dados segue os seguintes passos: inicialmente, coleta-se o snapshot do serviço Evo com todos os carros disponíveis no minuto corrente. Depois, é feita uma consulta à base de dados capturando os veículos disponíveis no minuto anterior. Para cada carro presente no minuto anterior, é verificado se o mesmo desaparece no minuto atual, nesse caso inicia-se um novo registro de viagem, com as últimas coordenadas conhecidas do veículo. Posteriormente, para cada carro do minuto atual, é verificado se ele não estava presente no minuto anterior, nesse caso, ele reapareceu. Dessa forma, os passos seguintes do algorítimo servem para guardar o destino final do registro de viagem.

Os dados coletados do Evo compreendem um período de 5 meses de coleta, de $1^{\circ}$ de Março de 2018 a 16 de Julho de 2018. É importante observar que, para não violar a privacidade dos usuários, não foram expostas nenhuma informação pessoal dos mesmos. Foram coletados aproximadamente 143 milhões de snapshots do serviço e 645 milhões de registros de viagens. O serviço apresenta 130 estações e 1237 veículos. Note que neste serviço não é necessário um grande número de estações devido a possibilidade de parada em estacionamentos públicos dentro da área delimitada de atuação do serviço. Esta área é chamada de home zone e cobre Vancouver e algumas cidades vizinhas.

A fim de compreender a demanda e as dinâmicas na área de atuação do serviço, buscou-se delimitar as regiões cujas características eram semelhantes. Isto é, foram utilizados dados que representam padrões de utilização dos veículos e não a divisão geopolítica da cidade. O método K-Means $\mathrm{S}^{2}$ foi utilizado para identificar essas regiões através de agrupamentos e, posteriormente, para discretização considerando o grupo mais predominante em certa região. Para o agrupamento foram considerados os seguintes parâmetros: duração da viagem, distância percorrida, período do dia em que a viagem foi iniciada (manhã, tarde, noite e madrugada) e coordenadas de início e fim das viagens. Entretanto, para realização do agrupamento, foi necessária uma pré etapa de limpeza, adequação e normalização nos dados. Portanto, foram removidas viagens que duraram menos de 30 minutos e percorreram menos de 3 metros uma vez que, tais características são atribuídas à viagens canceladas. Então, os dados foram divididos em dias de semana e fins de semana. Além disso, a hora de início das viagens foi discretizada para o formato manhã, tarde, noite ou madrugada.

Para determinar um número mais adequado de grupos foi utilizado o método $E l$ bow. A Figura 2 mostra a execução do método para dias de semana e finais de semana.

\footnotetext{
${ }^{2}$ Em mineração de dados, o k-means é um método de clusterização que objetiva particionar $\mathrm{n}$ observações dentre k grupos onde cada observação pertence ao grupo mais próximo da média.
} 
Para cada $\mathrm{k}$ foram executadas 30 iterações do K-Means, ao todo foram testados 25 valores diferentes para $\mathrm{k}$. Como pode ser observado, ambos períodos obtiveram figuras semelhantes, assim foi escolhido o número 7 para o valor de $\mathrm{K}$, pois a partir desse valor as distâncias dos erros quadráticos se estabilizam.

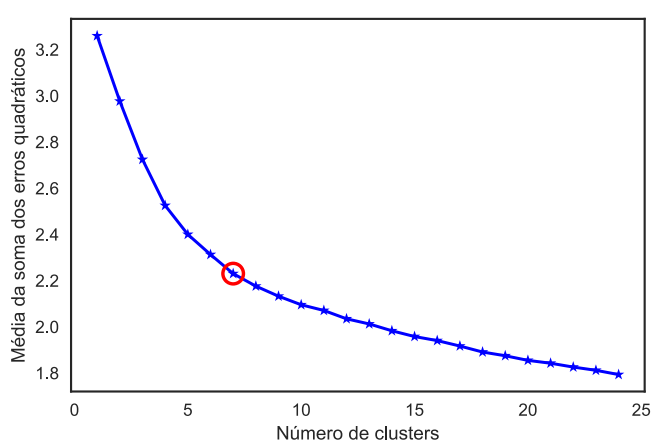

(a) dias de semana.

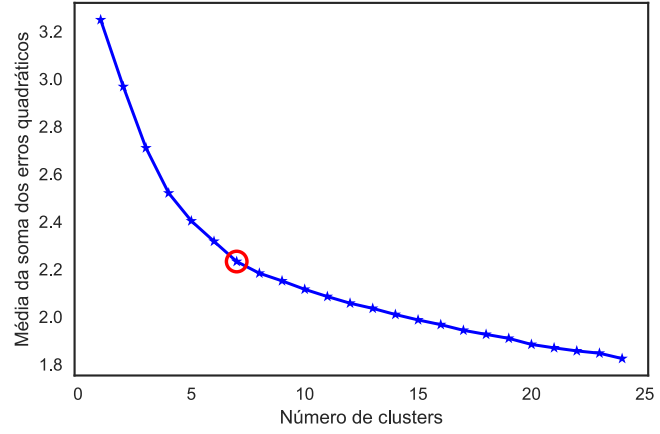

(b) finais de semana.

Figura 2. Método Elbow para clusterização K-Means.

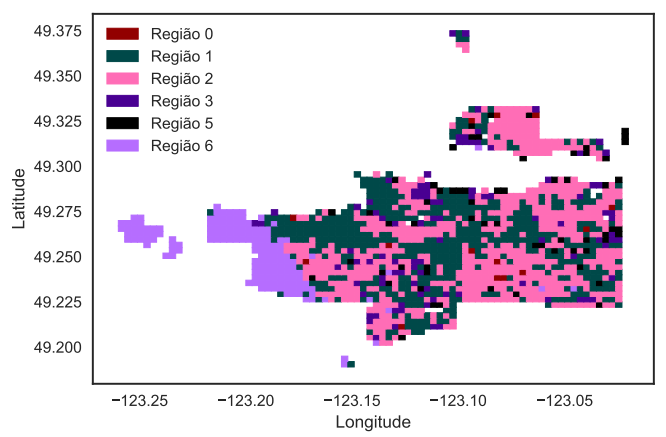

(a) dias de semana.

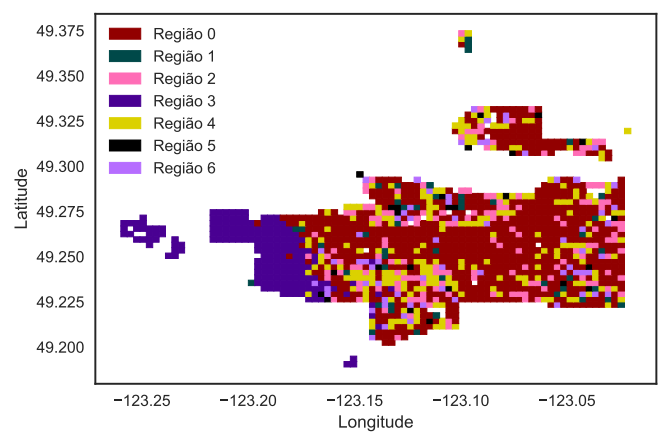

(b) finais de semana.

Figura 3. Regiões de atuação por grupo para dias de semana e fins de semana.

Para uma visualização mais clara dos grupos no mapa, os pontos correspondentes a cada grupo foram discretizados de acordo com o grupo de maior predominância em dada região. Foi montada uma malha dividida em quadrantes de 200x200 metros sobre a cidade. Após isso, foi identificado, em cada quadrante, qual grupo teve mais ocorrências de viagens iniciadas dentro da área delimitada pelo quadrante. Assim, definiu-se que a região do quadrante trata-se de uma área de atuação do grupo identificado. A Figura 3, apresenta as regiões discretizadas pelo método anterior, onde a região associada ao "Grupo 0" é identificada por "Região 0", a região associada ao "Grupo 1" é identificada por "Região 1 " e assim sucessivamente. Nesse processo de discretização, o Grupo 4, que deveria ser representado pela Região 4 foi eliminado. Isso aconteceu porque em nenhum quadrante, o Grupo 4 teve uma quantidade predominante de viagens.

\section{Resultados}

Nesta seção, é apresentada uma caracterização dos dados que apoiam o Módulo de Demanda Offline (Seção 2). A partir da análise dos grupos foi possível identificar padrões 
de demanda espaço-temporais. Todas as análises e informações levantadas poderão ser utilizadas para a criação de modelos de predição e também para a alimentação de um Módulo de Otimização Online.

A Figura 3 -a, apresenta três grandes regiões e outras duas mais dispersas pelo mapa. Além disso, nota-se que o grupo 4 desaparece, pois, durante o processo de discretização ela não obteve maioria de ocorrências em nenhum quadrante analisado. A Figura 3 b, mostra que aos finais de semana, as regiões tendem a ser mais dispersas, apresentando somente duas regiões majoritárias e, nesse caso sem perda de nenhum grupo pelo processo de discretização.

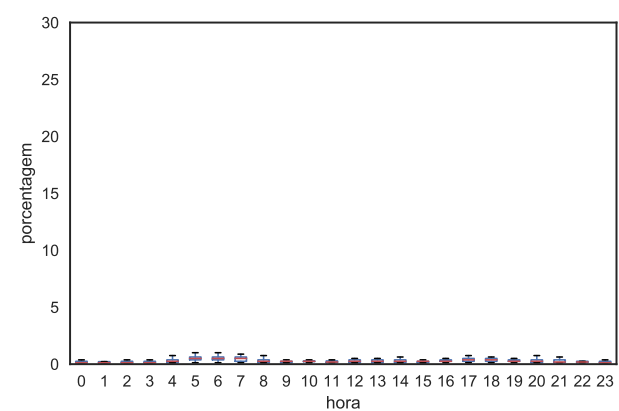

(a) Região 0

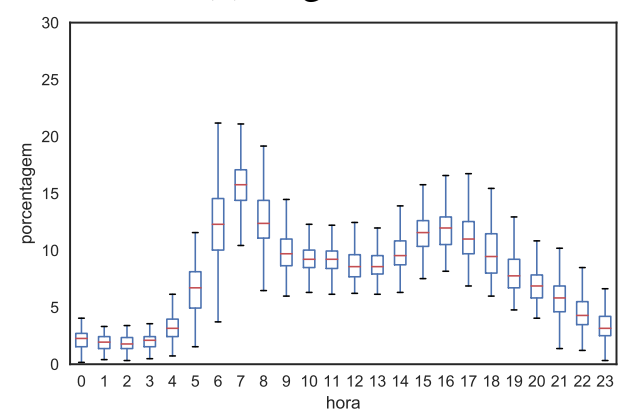

(c) Região 2

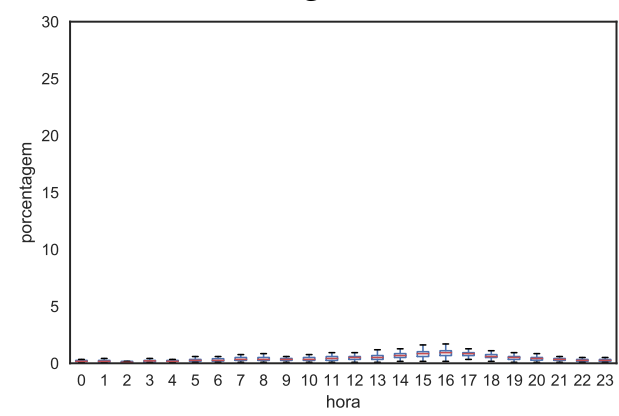

(e) Região 5

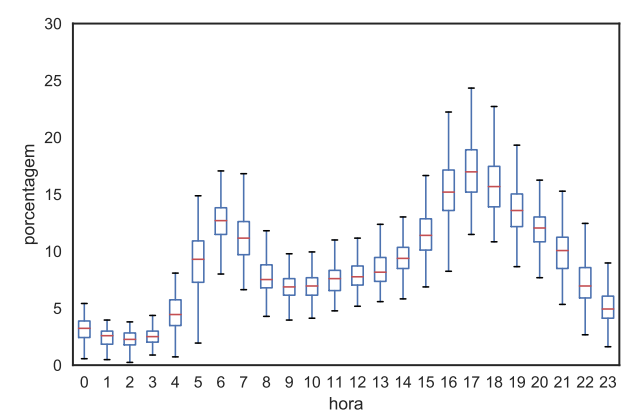

(b) Região 1

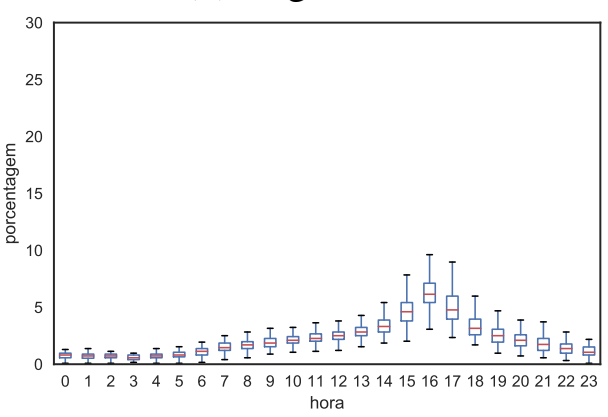

(d) Região 3

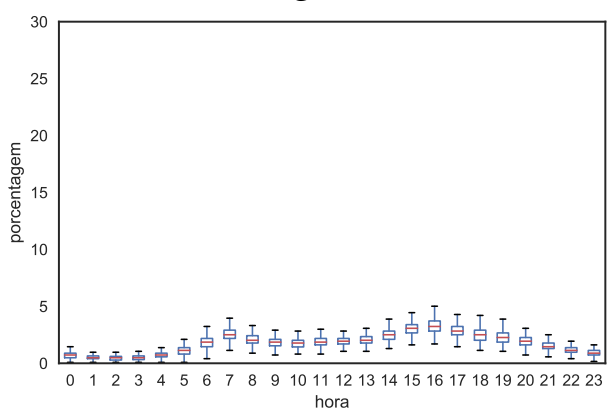

(f) Região 6

Figura 4. Percentual de veículos ocupados em dada hora para cada região em relação a área total observada, em dias de semana.

As Figuras 4 e 5 apresentam os aspectos temporais da demanda dos veículos do serviço dentro de cada região. Elas apresentam a porcentagem de ocupação de veículos a cada hora em relação ao todo. Tal abordagem contribui com informações sobre padrões de demanda de veículos ao longo do dia e picos de utilização. A Figura 4 mostra que 


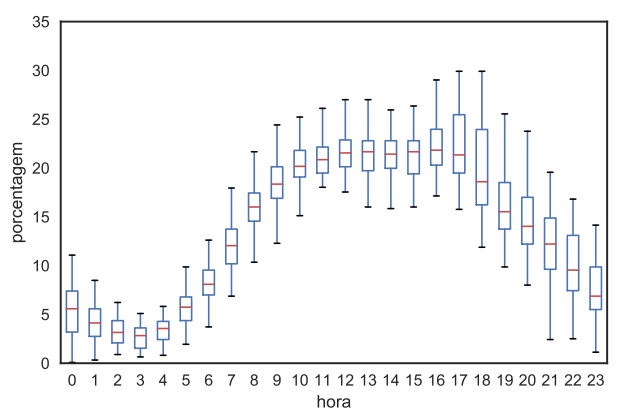

(a) Região 0

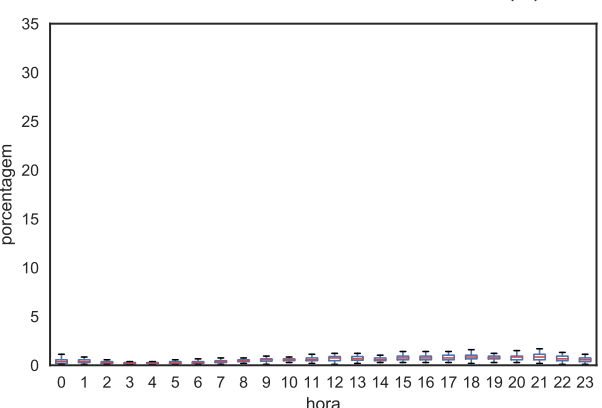

(b) Região 1

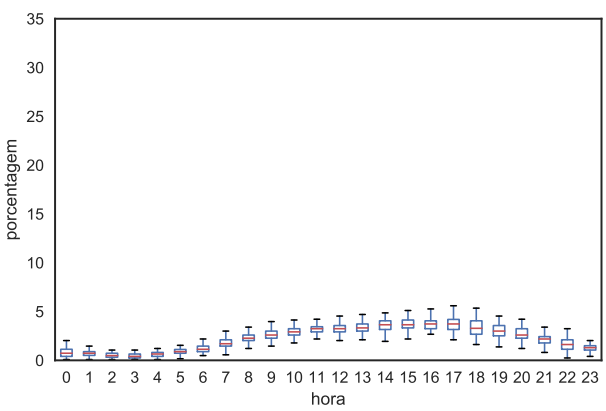

(d) Região 3

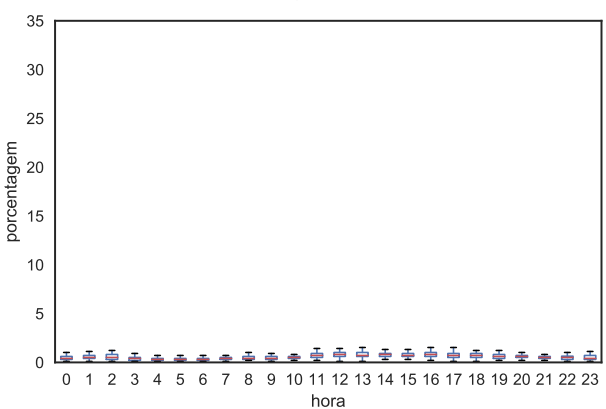

(f) Região 5

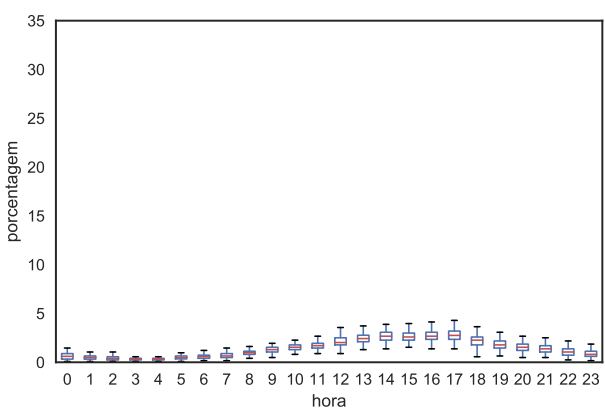

(c) Região 2

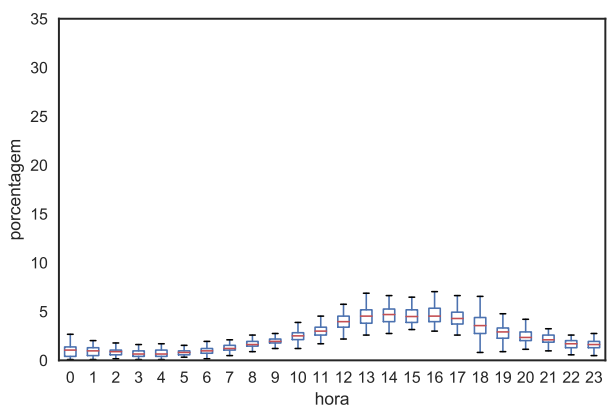

(e) Região 4

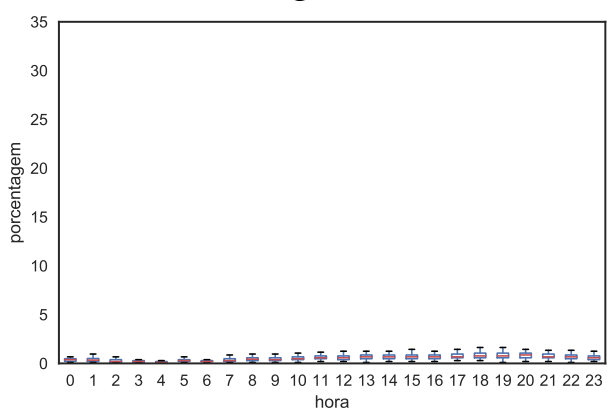

(g) Região 6

Figura 5. Percentual de veículos ocupados em dada hora para cada região em fins de semana.

as regiões 1 e 2 apresentam picos em horários coincidentes a rotinas laborais em dias de semana. No entanto a região 1 detém um pico mais significativo no período da tarde e a região 2 no período da manhã. A Figura 5 mostra que a utilização dos finais de semana tem um comportamento crescente ao longo do dia, com um pico de utilização que se 
prolonga durante todo o período da tarde - como pode ser visto na região 1 . Também é possível notar que a porcentagem de ocupação tem uma relação proporcional ao tamanho de cada região, tanto para dias de semana quanto fins de semana. De fato, quanto menor a região, menor é a porcentagem do total de veículos do serviço ocupados nela.

A Figura 6 apresenta a duração das viagens iniciadas em cada região. Na Figura 6 a, percebe-se que todas as regiões seguem um padrão semelhante de tempo de ocupação, onde $50 \%$ das viagens detém menos de 30 minutos de duração. Um padrão semelhante também pode ser observado na Figura 6 , que representa os fins de semana. Assim, notase que o padrão de duração de viagens nas regiões definidas são homogêneos e que suas viagens são majoritariamente, de curta a média duração.

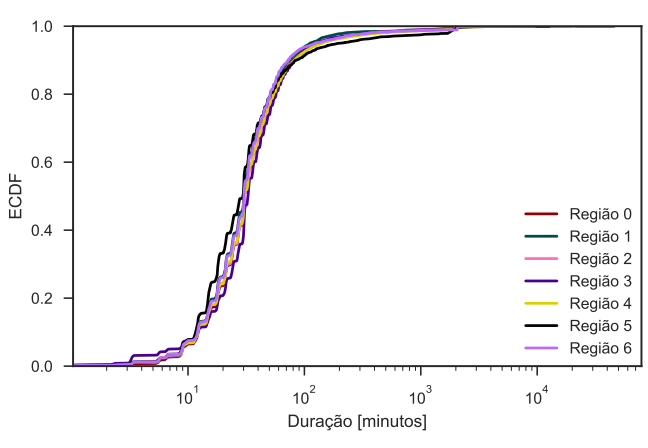

(a) dias de semana.

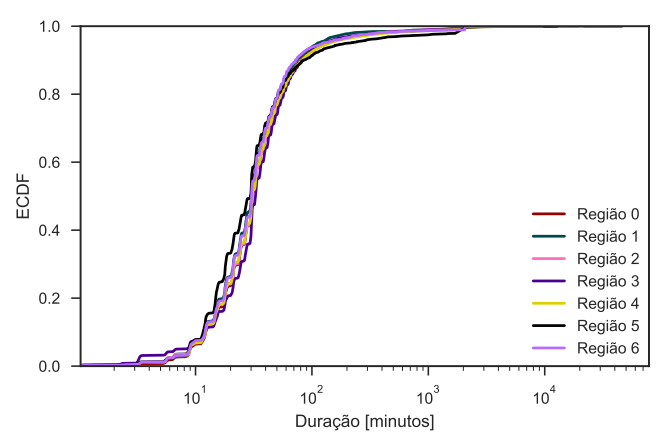

(b) finais de semana.

Figura 6. Função de Distribuição Acumulada do tempo de ocupação de veículos.

Além da ocupação, a ociosidade dos veículos dentro de cada região também foi analisada. Compreender o padrão de ociosidade de cada região a auxilia na descoberta da dinâmica de alocação dos veículos. Em outras palavras, uma maior ociosidade de veículos em regiões, cujo padrão de ociosidade é baixo, é um indicativo da necessidade de realocação dos veículos dessas regiões. Portanto, foram geradas as Figuras 7 e 8 A Figura 7, apresenta, como esperado, picos inversos a ocupação (Figura 4) nas regiões de maior movimentação, além disso, percebe-se que a taxa de ociosidade ao longo do dia é alta. Na Figura 8, nota-se, novamente, a predominância de uma região com elevadas quantidades de veículos ociosos ao longo do dia.

Os tempos de ociosidade dos veículos de cada região são apresentados na Figura9. Para ambas figuras, o comportamento entre regiões é semelhante. A Figura 9-a, mostra que $60 \%$ dos veículos ficam até 1 hora e 40 minutos ociosos. Um comportamento semelhante acontece na Figura 9-b, que representa finais de semana. Menos de $10 \%$ dos casos tem tempos de ociosidade maiores que 24 horas. Esses valores também podem ser utilizados para a identificação de anormalidades e serem transformados em gatilhos para algorítimos de realocação. Como exemplo, tem-se a situação em que mais de $10 \%$ dos veículos de determinada região se encontram ociosos por mais de um dia, indicando uma anormalidade e uma possível necessidade de realocação.

A movimentação entre regiões é apresentada na Figura 10. Esta figura apresenta uma matriz de origem-destino das regiões anteriormente estabelecidas. Os dados foram normalizados em uma escala de 0 a 1 , utilizando o método min-max. $\mathrm{O}$ entendimento da dinâmica entre as regiões oferece suporte a possíveis estratégias de realocação. 


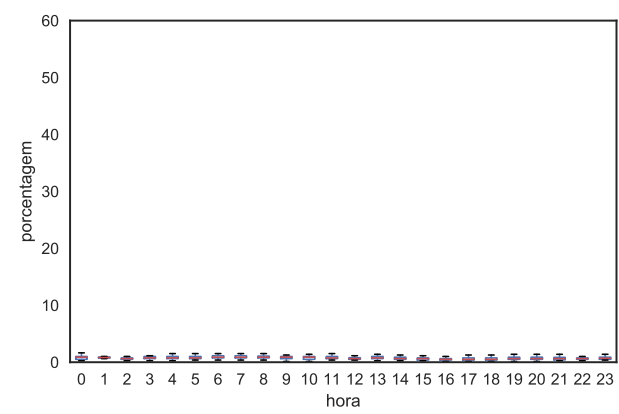

(a) Região 0

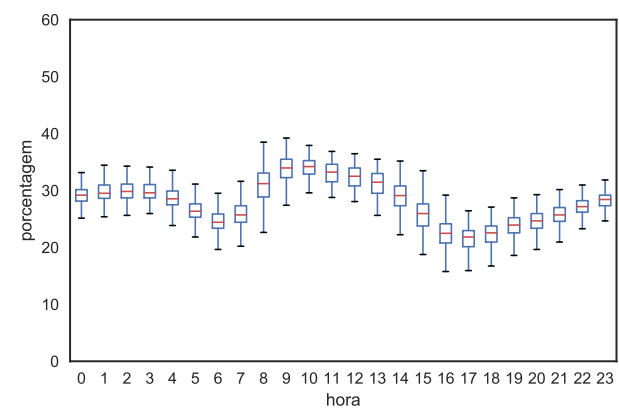

(c) Região 2

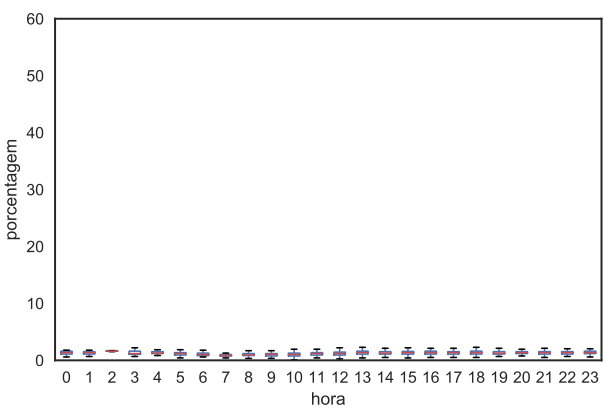

(e) Região 5

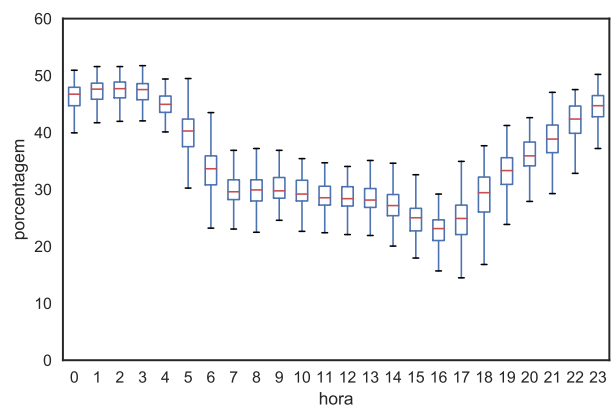

(b) Região 1

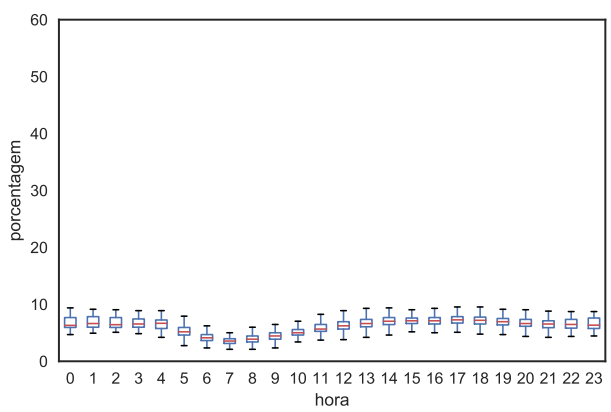

(d) Região 3

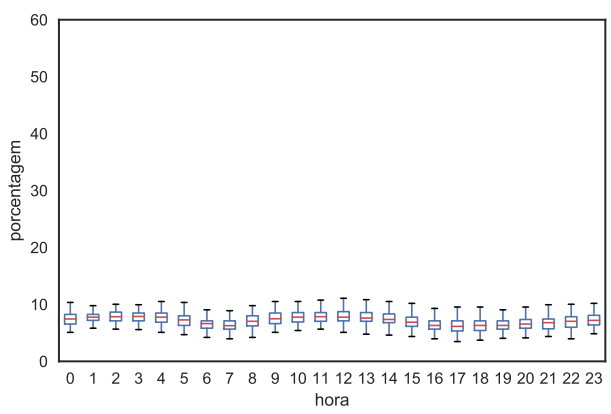

(f) Região 6

Figura 7. Percentual de veículos ociosos em dada hora para cada região em dias de semana.

Para dias de semana, a Figura 10 a, mostra um forte movimento de saída da região 1 e 2 comparado as demais, contudo não há grandes movimentações de retorno. Para fins de semana, a Figura 10-b, apresenta uma única região com maior movimentação de saída. Ainda, a Região 3, detém uma grande movimentação sobre si mesma, assim, novamente tem-se grandes movimentações de saída de determinada região, porém sem grandes fluxos de retorno. Além disso, é importante notar que há grandes fluxos dentro das regiões para dias de semana e pouco para fins de semana. Tal comportamento aos fins de semana pode gerar problemas de alocação dos veículos sobre o início dos dias de semana.

As distâncias percorridas nas viagens realizadas são apresentadas na Figura 11. É importante ressaltar que, para o cálculo das distâncias, foi utilizado a distância geodésica entre os pontos de início e fim das viagens. Essa distância representa um limite inferior da distância real percorrida. Não é possível conhecer a distância real, uma vez que o serviço não disponibiliza os trajetos dos veículos alugados. A Figura 11 -a, mostra que em $60 \%$ dos casos, as regiões 2, 3 e 5 seguem um padrão similar, onde os trajetos apresentam até 


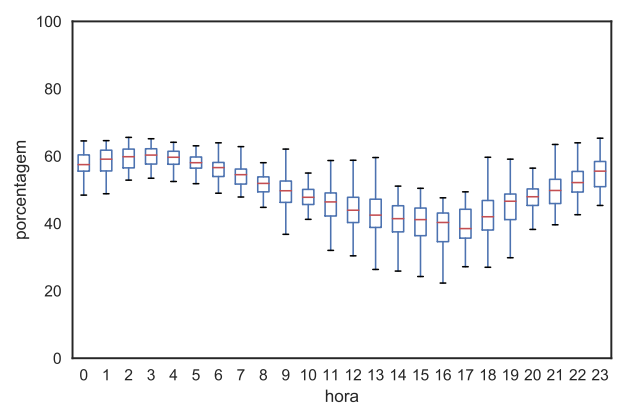

(a) Região 0

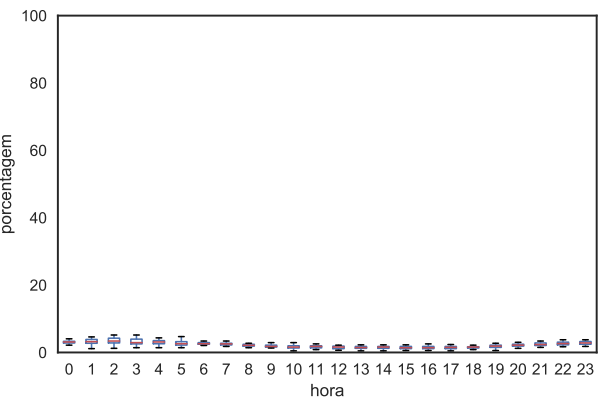

(b) Região 1

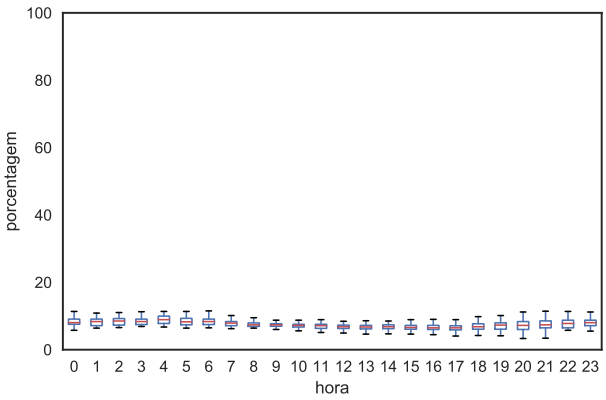

(d) Região 3

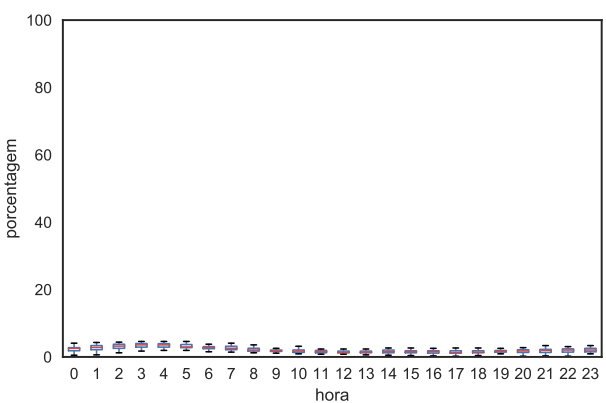

(f) Região 5

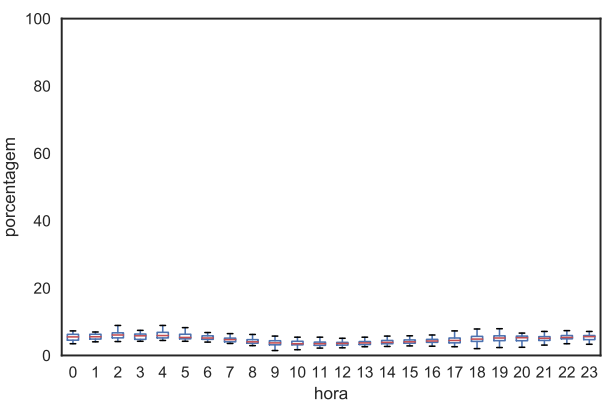

(c) Região 2

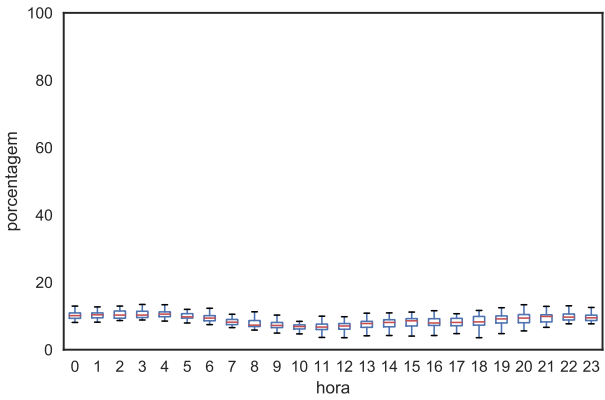

(e) Região 4

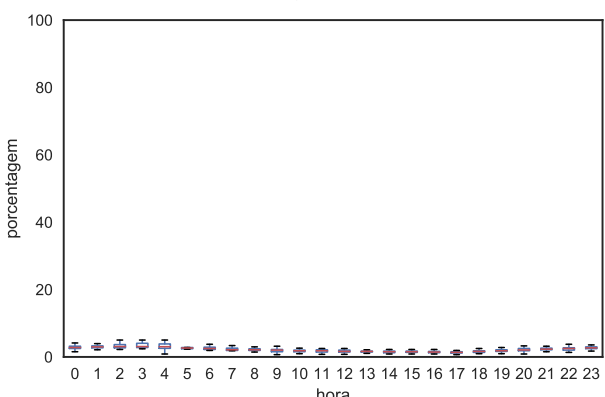

(g) Região 6

Figura 8. Percentual de veículos ociosos em dada hora para cada região em fins de semana.

$3 \mathrm{Km}$. A região 0 e 6 começam a destoar das demais aos 30\%. Notadamente, apresentam trajetos mais longos que as demais. Por exemplo, em $60 \%$ dos casos a região 0 apresenta viagens com trajetos de até $4 \mathrm{Km}$ enquanto na região 6, esse numero cresce para até $6 \mathrm{Km}$. $\mathrm{Na}$ Figura 11 b observa-se que as regiões seguem um padrão semelhante, onde $60 \%$ dos viagens tem trajetos de até $3 \mathrm{Km}$. A Região 3, nesse caso, apresenta viagens mais longas 


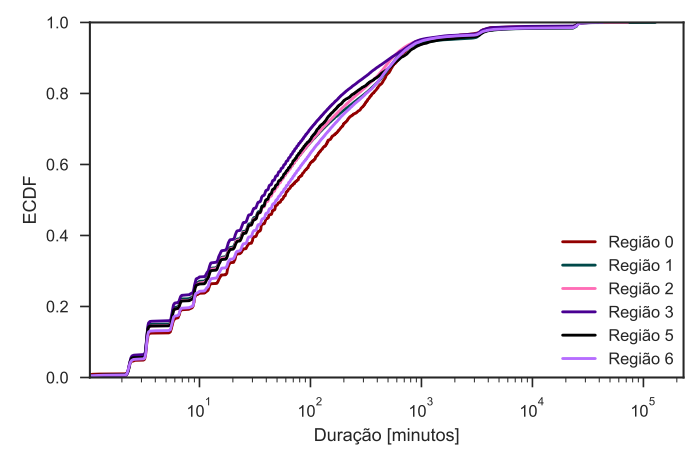

(a) dias de semana.

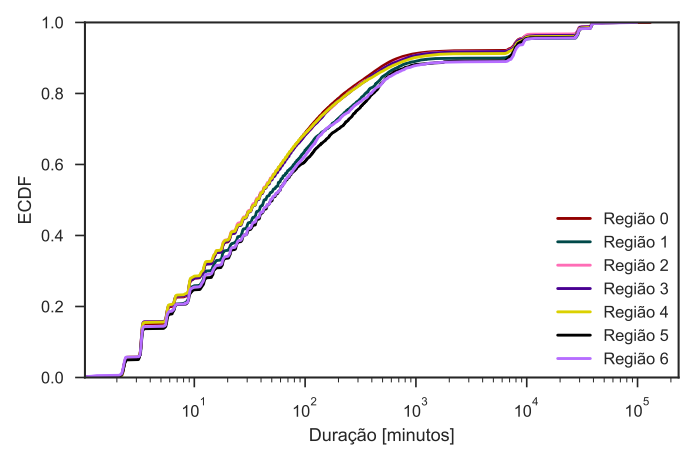

(b) finais de semana.

Figura 9. Função de Distribuição Acumulada do tempo de ociosidade de veículos.

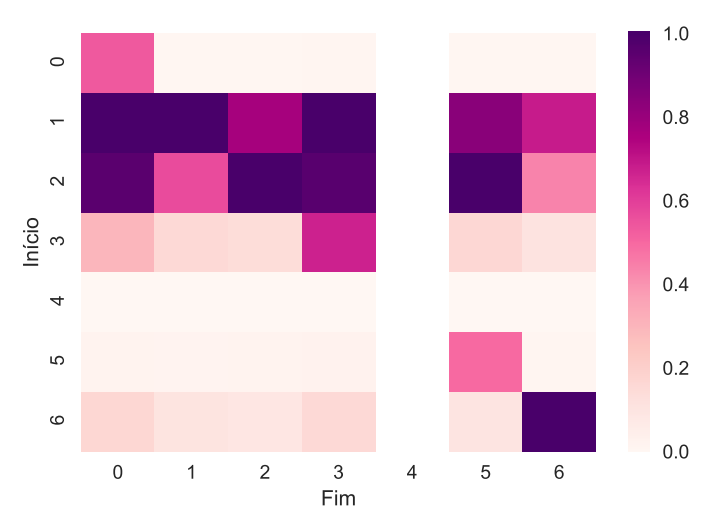

(a) dias de semana.

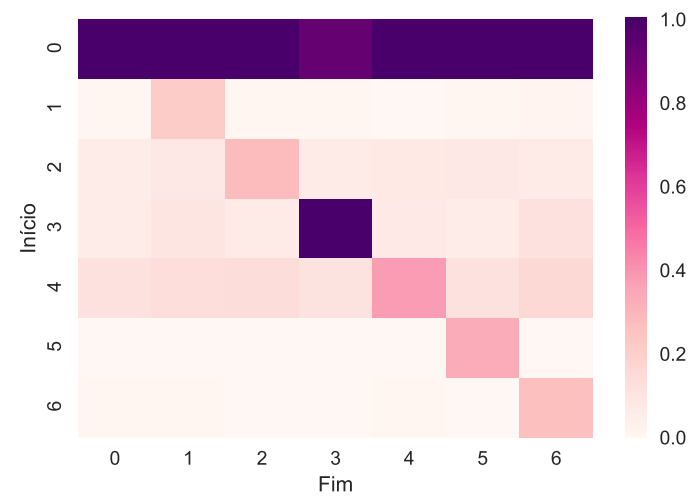

(b) finais de semana.

Figura 10. Matriz de origem-destino das regiões.

que as demais. Por exemplo, $60 \%$ dos viagens tem trajetos de até $5 \mathrm{Km}$. Por fim, é interessante observar que tanto a Região 6, nos dias de semana, quanto a Região 5, aos finais de semana, tem comportamentos semelhantes. Conjectura-se que a característica de utilização para viagens mais longas, possa estar associada ao público universitário, característico das áreas compreendidas por essas regiões.

\section{Discussão e Trabalhos Futuros}

A partir das caracterizações apresentadas na seção anterior é possível reafirmar o problema de realocação bem como criar estratégias visando melhor direcionamento das realocações através de cada região, dia da semana e horário.

Em um primeiro momento, a partir das observações, uma solução plausível seria incluir operadores nas principais regiões em momentos de ociosidade de veículos que antecedam os horários de pico. Esses operadores seriam responsáveis por transportar os veículos entre regiões de forma que o sistema se mantenha estável em relação a demanda e oferta. Assim, os operadores deveriam ser munidos de um dashboard que contemple, em tempo real, os dados da caracterização. Todavia, a intervenção em um sistema de compartilhamento de carros é sempre acompanhada de custos. Portanto, a estratégia baseada 


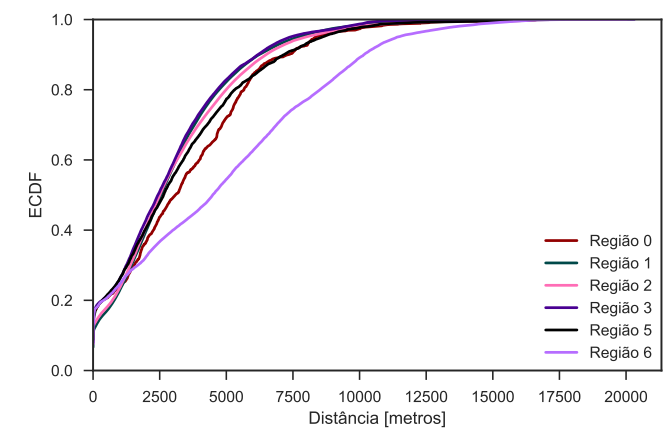

(a) dias de semana.

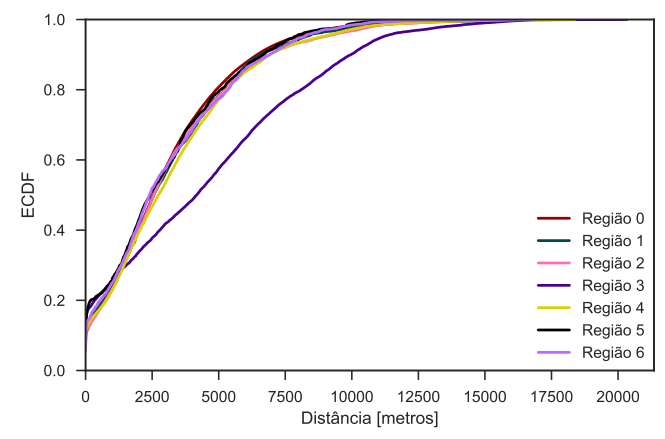

(b) finais de semana.

Figura 11. Função de Distribuição Acumulada da distância percorrida pelos veículos.

em operadores deve ser cautelosa. Para esse cenário, vislumbra-se que os serviços de compartilhamento de carro, poderiam também ofertar serviços de transporte privado para pontos específicos. Ou seja, operadores poderiam trabalhar como motoristas particulares em pontos específicos amenizando, através desses ganhos, o custo de mão de obra com recursos humanos. Essa ideia, pode servir como um agente de marketing para o serviço, englobando uma nova parcela de interessados.

Visando uma realocação, na maioria das vezes mais econômica, cogita-se a utilização de mão de obra do próprio usuário. Assim, vale-se apoiar em estratégias de gameficação onde o usuário recebe recompensas por prestar serviços. De acordo com a caracterização apresentada seria interessante oferecer descontos em locação de veículos àqueles usuários que estejam em regiões propensas a terem sobrecarga. Portanto, esses usuários, seriam notificados a partir de seus smartphones sobre descontos para transportar um carro de uma região A para uma região B. Neste cenário, obter informações de contexto do usuário a partir de outros serviços, tal qual o Google Maps se mostra uma estratégia interessante visando ofertas mais assertivas. Isto é, o usuário $\mathrm{X}$ deverá receber propostas de deslocamento, diferentes do usuário Y baseado nos seus trajetos cotidianos e localização atual. Comparada à abordagem baseada em operadores, vale-se, inclusive, a oferta de corridas gratuitas para os pontos críticos.

Uma possível implementação das concepções anteriores, deverá utilizar as restrições demonstradas na caracterização e tomar decisões com relação a uma estratégia baseada no operador, usuário ou híbrida. Portanto, o algoritmo deverá receber como parâmetros o estado de cada região - outros serviços também podem ser utilizados, por exemplo, APIs de previsão do tempo - com quantificadores, o horário, o dia da semana, entre outros. $\mathrm{O}$ algoritmo retornará que realocações devem ser realizadas para atender a demanda recebida. Com esse retorno o sistema irá tomar decisão e contactar os usuários através de notificações (inteligentes), oferecendo trabalhos e/ou recompensas.

\section{Conclusão}

A mobilidade urbana se torna cada vez mais um corpo de pesquisa interessante em diversas áreas do conhecimento. Todavia, a aquisição de dados atuais e acurados ainda é um desafio neste cenário, dificultando a criação de propostas mais assertivas. Os sis- 
temas de compartilhamento de veículos representam um tópico interessante relacionado à mobilidade urbana. Entretanto, devido a uma demanda de saída elevada de veículos em determinados locais, e a uma entrada não equivalente, possivelmente menor, alguns locais podem ficar desabastecidos. Por outro lado, outras localizações cuja demanda de saída não é elevada, podem ficar com veículos em excesso. Neste trabalho foram apresentados aspectos relacionados ao problema de realocação de veículos, bem como a caracterização do Evo, um serviço de uma via híbrido. Nessa caracterização foram discretizados parâmetros importantes que servirão de apoio a tomada de decisão em propostas de soluções do problema. Finalmente, foram apresentadas estratégias e trabalhos futuros visando posteriores implementações. Assim, este trabalho representa um importante passo para o entendimento e evolução de sistemas de compartilhamento de veículos, fornecendo um apanhado de informações que podem ser utilizadas para criação de modelos e Frameworks genéricos relacionado a esse tipo de sistema.

\section{Referências}

Becker, H., Ciari, F., and Axhausen, K. W. (2017). Comparing car-sharing schemes in switzerland: User groups and usage patterns. Transportation Research Part A: Policy and Practice, 97:17-29.

Boldrini, C., Bruno, R., and Conti, M. (2016). Characterising demand and usage patterns in a large station-based car sharing system. In Computer Communications Workshops (INFOCOM WKSHPS), 2016 IEEE Conference on, pages 572-577. IEEE.

Ciociola, A., Cocca, M., Giordano, D., Mellia, M., Morichetta, A., Putina, A., and Salutari, F. (2017). Umap: Urban mobility analysis platform to harvest car sharing data. In 2017 IEEE SmartWorld, Ubiquitous Intelligence Computing, Advanced Trusted Computed, Scalable Computing Communications, Cloud Big Data Computing, Internet of People and Smart City Innovation (SmartWorld/SCALCOM/UIC/ATC/CBDCom/IOP/SCI), pages 1-8.

Herrera, J. C., Work, D. B., Herring, R., Ban, X. J., Jacobson, Q., and Bayen, A. M. (2010). Evaluation of traffic data obtained via gps-enabled mobile phones: The mobile century field experiment. Transportation Research Part C: Emerging Technologies, 18(4):568-583.

Kek, A. G., Cheu, R. L., Meng, Q., and Fung, C. H. (2009). A decision support system for vehicle relocation operations in carsharing systems. Transportation Research Part E: Logistics and Transportation Review, 45(1):149-158.

Ma, S., Zheng, Y., and Wolfson, O. (2013). T-share: A large-scale dynamic taxi ridesharing service. In Data Engineering (ICDE), 2013 IEEE 29th International Conference on, pages 410-421.

Nourinejad, M. (2014). Dynamic optimization models for ridesharing and carsharing. Master's thesis, University of Toronto.

Shaheen, S. A. (2016). Mobility and the sharing economy. Transport Policy, 51(Supplement C): 141 - 142 .

Weikl, S. and Bogenberger, K. (2013). Relocation strategies and algorithms for freefloating car sharing systems. IEEE Intelligent Transportation Systems Magazine, 5(4):100-111. 